TITLE:

\title{
Simulation of flying debris using a numerically generated tornado-like vortex
}

\author{
$\operatorname{AUTHOR}(\mathrm{S})$ :
}

Maruyama, Takashi

\section{CITATION:}

Maruyama, Takashi. Simulation of flying debris using a numerically generated tornadolike vortex. Journal of Wind Engineering and Industrial Aerodynamics 2011, 99(4): 249-256

\section{ISSUE DATE:}

2011-04

URL:

http://hdl.handle.net/2433/141803

\section{RIGHT:}

(C) 2011 Elsevier Ltd.; This is not the published version. Please cite only the published version.; この論文は出版社版でありません。引用の際に は出版社版をご確認ご利用ください。 


\title{
Simulation of flying debris using a numerically generated tornado-like vortex
}

\author{
Takashi Maruyama
}

Associate Professor, Disaster Prevention Research Institute, Kyoto University

Ujishi Gokasyo, Kyoto 611-0011, Japan, maruyama@scl.kyoto-u.ac.jp

Tel:+81-774-38-4167, Fax:+81-774-38-4170

\begin{abstract}
A study on the trajectory of flying debris in a tornado-like vortex was carried out by numerical simulation. A numerical tornado simulator was developed, which has the equivalent configuration to the laboratory experiment. Numerical calculations were done by Large Eddy Simulation and a series of unsteady flow fields of a tornado-like vortex was generated. Wind characteristics in the vortex were examined. Finally, three dimensional trajectories of flying debris were computed and the statistical distributions of the maximum horizontal speed of debris were obtained.
\end{abstract}

Keywords: Tornado-like vortex; Numerical simulation; Flying debris

\section{INTRODUCTION}

Many studies have been carried out on flying debris since the pioneering works of Tachikawa (Tachikawa, 1983) and Wills et al. (2002), which classified the types of debris and analyzed the flight conditions and the resulting building damage. Trajectories of 'compact' type (English et al., 2005; (Holmes, 2004. etc.), 'sheet' type (Holmes et al., 2004; Tachikawa, 1983; Wang and Letchford, 2003. etc.) and 'rod' type (Lin et al., 2007; Richards et al., 2008) of debris have been considered, but none of these studies have been carried out under the flow conditions of a tornado. (Simiu et al. (1976) computed the trajectory in a tornado with a Rankine vortex. Recent research on tornadoes has progressed and we can obtain information of their flow fields. Especially useful are the computational studies which provide records of three dimensional velocity fields. These enable us to simulate the dynamics of flying debris in a tornado. Kuai et al. (2008) studied a laboratorysimulated tornado using the $\mathrm{k}-\varepsilon$ turbulence model and obtained mean velocity fields. On the other hand, Maruyama (2009) generated the unsteady velocity field of a tornado-like vortex by Large Eddy Simulation. The instantaneous velocity records generated in a numerical tornado simulator were used to compute and examine the trajectories of flying debris. 


\section{COMPUTATION OF A VORTEX}

\subsection{Numerical tornado simulator}

The numerical calculation of a tornado-like vortex by Large Eddy Simulation (hereafter abbreviate LES) was arranged to obtain the unsteady wind field (Maruyama 2009). The calculation region was designed to correspond with a laboratory simulator (Monji et al. 1985) which consists of a convection region and a convergence region as shown in Fig. 1. A calculation mesh with $91 \times 91 \times 89$ cells for $X, Y$ and $Z$ directions was used. The preliminary calculations with a variety of mesh sizes and numbers indicate that the calculated flow fields have little change with the finer meshes than that used here. The minimum width of the calculation mesh size is $1 / 8$ of the radius of the maximum tangential speed of the vortex. The details of these calculations are discussed in Maruyama (2009).

\section{Fig. 1.}

\subsection{Governing equations}

The governing equations consist of filtered mass and momentum conservation equations as given by Equations (1) and (2) below:

$$
\begin{aligned}
& \frac{\partial U_{j}}{\partial X_{j}}=0 \\
& \frac{\partial U_{i}}{\partial t}+\frac{\partial U_{i} U_{j}}{\partial X_{j}}=-\frac{1}{\rho} \frac{\partial P}{\partial X_{i}}+\frac{\partial 2 v_{e} \bar{D}_{i j}}{\partial X_{j}}
\end{aligned}
$$

where all variables are spatially averaged quantities. $i, j=1,2,3, X_{1}, X_{2}$ and $X_{3}$ are $X, Y$ and $Z$, respectively. $U_{i}$ is the $X_{i}$-component of velocity, $\rho$ the air density, $P$ the pressure, $v_{e}$ the effective viscosity which is sum of the viscosity $v$ and the sub-grid scale viscosity $v_{S G S} \cdot \bar{D}_{i j}$ and $v_{S G S}$ are defined as:

$$
\begin{aligned}
& \bar{D}_{i j} \equiv \frac{1}{2}\left(\frac{\partial U_{i}}{\partial X_{j}}+\frac{\partial U_{j}}{\partial X_{i}}\right) \\
& v_{S G S} \equiv\left(C_{S} L\right)^{2}|\bar{D}|,|\bar{D}| \equiv \sqrt{2 \bar{D}_{i j} \bar{D}_{i j}}
\end{aligned}
$$

where $C_{S}=0.1$ following the standard Smagorinsky turbulent model. We conducted the numerical calculation with a finite difference method and related the averaging volume to the mesh volume $\Delta X_{1} \Delta X_{2} \Delta X_{3}$ where $\Delta X_{i}$ is the $X_{i}$-directional width of mesh discretization. Additionally we related the filter width $L$ as:

$$
L \equiv \sqrt[3]{\Delta X_{1} \Delta X_{2} \Delta X_{3}}
$$




\subsection{Calculation method}

The calculating scheme used here is based on RIAM-COMPACT (Uchida et al. 2003) developed at Kyusyu University. The governing equations were approximated by a finite difference scheme. An orthogonal grid with a staggered mesh system was used for the arrangement of parameters. A second-order centered difference scheme mentioned by Kajishima (1999) was adopted for spatial derivatives. The Adams-Bashforth scheme was employed for time-marching. Numerical integrations were conducted according to the fractional step method for mass flux and pressure coupling.

The horizontal wind shear was supplied by inflows on the side walls of the convergence region. An example of a vortex generated with an inlet boundary condition is also presented in Fig. 1. The Dirichlet condition areas where certain velocities were distributed, the free condition areas where the normal gradient of velocity was set to be zero and the non-slip condition areas where the velocity was set to be zero were laid out on the side wall of the convergence region. The strength of vorticity was controlled by the wind speed and the layout of the inflow conditions. The inflow velocities were arranged so as to conserve the total mass flux over the calculation region if only the Dirichlet boundary conditions were used. The setup of these values and parameters are listed in Table 1.

\subsection{Generated vortices}

A series of unsteady vortex flow fields were generated and the flow characteristics were examined for various calculation conditions. Some typical vortex types are presented in Fig. 2 to 5 and the corresponding parameters and conditions are summarized in Table 1. The swirl ratio $S$ is defined as $\pi R_{\mathrm{tm}}{ }^{2} V_{\text {tmax }} / Q$ where $Q$ is the total outflow rate, $=\pi R_{\mathrm{t}}{ }^{2} W_{0}$, at the top exhaust of the convection region of tornado simulator. $R_{\mathrm{tm}}$ is the radius where the maximum value of the maximum mean tangential speed $V_{\operatorname{tmax}}$ occurred. The Reynolds number $R$ e is defined as $V_{\mathrm{tmax}} R_{\mathrm{tm}} / v . \quad v$ is the viscosity of the air. The averaged value of mean pressures at the corners of convergence region was chosen as the reference pressure for indicating the contour surface of low pressure regions in Figure 2-5. Hereafter 'mean' denotes time averaging. The vortices include a single core type vortex with a narrow convection region as shown in Fig. 2. The center of the vortex core stays almost at a point and does not have a down-flow region, indicated by a non-negative mean vertical velocity component in the core. A single core type vortex with a down-flow region in the core: i.e. two cell type is generated with a wide convection region as shown in Fig. 3. The flow near the ground in the core is more turbulent than the vortex shown in Fig. 2 and the center of vortex core is fluctuating. A multi-core type vortex with multiple suction vortices is simulated with the calculation region of a wide convection region and a relatively thin convergence region as shown in Fig. 4. A swirling core type with a swirling low pressure core is generated with the configuration of calculation region as shown in Fig. 5. Large vorticity and tangential speed are observed in the core of vortex with the large wind shear in the Dirichlet boundary on the side wall of convergence region.

Table 1.

Fig. 2. 


\section{Fig. 3.}

\section{Fig. 4.}

Fig. 5.

A two cell type vortex (Fig. 3) was chosen for the following computation of flying debris. The flow characteristics of the vortex are shown in Fig. 6. Strong radial mean flow directed toward the center of vortex is present near the ground (Fig. 6d). Above it, there is a region of strong tangential mean flow (Fig. 6c). A profile of the maximum tangential speed radius $R_{\mathrm{tm}}$ at which the maximum mean tangential speed occurs is plotted by a broken line in the Fig. 6c. A strong updraft region is observed inside of the strong tangential speed region (Fig. 6e) and the flow directs outward above the strong updraft region (Fig. 6d) which corresponds to the value of mean horizontal wind angle $\alpha$ less than 90 degree shown in Fig. 6b. Figure of $\alpha$ indicates larger value than 90 degree near the center of vortex, which means the mean flow directs toward the center. A down flow region with weak negative mean vertical speed can be observed in the core of vortex (Fig. 6e). Instantaneously, positive radial speed can be observed near the ground (Fig. 6g) and negative tangential speed can be observed in the core (Fig. 6i).

As shown in Fig. 7 the maximum mean tangential speed $V_{\mathrm{tm}}(\mathrm{z})$ increases with height near the ground and after having the maximum value $V_{\text {tmax }}$ at $Z=0.3 R_{\text {tmax }}$ decreases and has a constant value of about $0.8 V_{\text {tmax }}$ above $Z=1.2 R_{\text {tmax }}$, where $R_{\text {tmax }}$ is the radius at which $V_{\text {tmax }}$ occurs. Profiles of the maximum tangential speed radius $R_{\mathrm{tm}}$ at which the maximum mean tangential speed occurs, the mean radial speed $V_{\mathrm{rm}}$ and the mean vertical speed $W_{\mathrm{m}}$ at $R_{\mathrm{tm}}$ are also plotted in Fig. 7. Also included is the swirl ratio $S$. The maximum tangential speed radius $R_{\mathrm{tm}}$ and the swirl ratio $S$ increase with height near the ground. After having maximum values at $Z=0.8 R_{\mathrm{tmax}}$ they decrease, and above $Z=1.2 R_{\mathrm{tmax}}$ they have constant values of $1.5 R_{\mathrm{tmax}}$ and 0.4 , respectively. The mean radial speed $V_{\mathrm{rm}}$ directs to the center of vortex near the ground, directs outward above the height of the maximum tangential speed and becomes near zero above $Z=0.8 R_{\text {tmax }}$. The mean vertical speed $W_{\mathrm{m}}$ is always positive with magnitude of around $0.1 V_{\mathrm{tmax}}$ to $0.2 V_{\mathrm{tmax}}$ along the maximum tangential speed radius.

\section{Fig. 6.}

\section{Fig. 7.}

The radial profiles of mean wind velocity and mean pressure at the height of the maximum mean tangential speed $V_{\text {tmax }}$ observed are plotted in Fig. 8 with the variation of core type. The normalized differential mean pressure $C_{\mathrm{p}}=2 \Delta P / \rho V_{\operatorname{tmax}}{ }^{2}$ indicates almost equivalent magnitude of -1.5 at the radius of $R_{\mathrm{tmax}}$ and also the absolute mean wind speed shows the half of the maximum mean tangential speed $V_{\text {tmax }}$ at the radius of $3 R_{\text {tmax }}$ irrespective of core type. Where $\Delta P$ is the differential mean pressure from the averaged value of mean pressures at the corners of convergence region.

As shown in Fig. 9 the simulated tangential wind speeds near ground resemble Rankine Vortex distribution in the region outside the vortex core of single core type and multiple core type. On the other hand the wind speed shows a wide variety of distributions in the 
region inside the vortex core. Experimental data with swirl ratio of 1.14 and the observed data (Kuai et al., 2008) also shows the equivalent distributions of single core type in the region outside the vortex core.

Fig. 8.

Fig. 9.

\section{COMPUTATION OF FLYING DEBRIS}

\subsection{Modeling of missile motion}

A piece of flying debris was assumed to be a 'compact' object which has a constant drag coefficient independent on the attack angle of the relative wind. The objects are accelerated by the aerodynamic force and become missiles. The acceleration of missiles $\tilde{\ddot{\mathbf{x}}}$ is given by:

$$
\tilde{\mathbf{x}}=C_{D} T_{a}\left|\tilde{\mathbf{v}}_{W}-\tilde{\mathbf{v}}_{M}\right|\left(\tilde{\mathbf{v}}_{W}-\tilde{\mathbf{v}}_{M}\right)-\mathbf{k}
$$

where $C_{\mathrm{D}}$ is the drag coefficient, $\widetilde{\mathbf{v}}_{W}$ and $\tilde{\mathbf{v}}_{M}$ are the velocity vectors of the surrounding wind and the missile, respectively. $\mathbf{k}$ is the unit vector along the vertical axis. $T_{\mathrm{a}}$ is the Tachikawa number (Holmes et al., 2006) defined as:

$T_{\mathrm{a}}=\frac{\rho A V_{0}^{2}}{2 m g}$

where $\rho$ is the air density, $A$ the characteristic area of missile, $V_{0}$ the characteristic wind speed, $m$ the mass of missile and $g$ the acceleration of gravity. $\left|\widetilde{\mathbf{v}}_{W}-\widetilde{\mathbf{v}}_{M}\right|$ is the magnitude of relative velocity between wind and missile defined as:

$$
\left|\tilde{\mathbf{v}}_{W}-\tilde{\mathbf{v}}_{M}\right|=\sqrt{\left(\tilde{u}_{W}-\tilde{u}_{M}\right)^{2}-\left(\tilde{v}_{W}-\tilde{v}_{M}\right)^{2}-\left(\tilde{w}_{W}-\tilde{w}_{M}\right)^{2}}
$$

The tilde denotes the dimensionless variables, created using the acceleration of gravity and the characteristic wind speed as follows:

$\tilde{\ddot{\mathbf{x}}}=\ddot{\mathbf{x}} / g, \quad \tilde{\mathbf{v}}_{M}=\mathbf{v}_{M} / V_{0}, \quad \tilde{\mathbf{v}}_{W}=\mathbf{v}_{W} / V_{0}, \quad \tilde{\mathbf{x}}=\mathbf{x} g / V_{0}^{2}, \quad \tilde{t}=\operatorname{tg} / V_{0}$

where $\mathbf{x}$ is the position, $\mathbf{v}_{M}$ the velocity and $\ddot{\mathbf{x}}$ the acceleration of missile. $\mathbf{v}_{W}$ is the wind velocity and $t$ is the time. Both $\mathbf{v}_{W}$ and $\mathbf{v}_{M}$ are referred to an absolute frame. The velocity $\mathbf{v}_{W}$ is specified as a sum of two parts. The first part represents the wind velocity of a stationary vortex and is referred to the system of coordinates shown in section 2 . The second part represents the translation velocity of the vortex with respect to an absolute frame of reference. 


\subsection{Calculations and numerical results}

We draw the characteristics of the vortex for numerical calculation from the design-basis tornado and tornado missiles for nuclear power plants in a regulatory guide (U. S. Nuclear Regulatory Commission, 2007). Table 2 lists the assumed characteristics of the vortex. Two types of missiles were selected for computations of flying debris as listed in Table 3. Missile A corresponds to a wooden plank and the other, Missile B, corresponds to an automobile. The spectrum of these missiles was taken from Simiu and Scanlan (1996). Also included in Table 3 are the parameter $C_{\mathrm{D}} A / m$ and the estimated maxima of maximum horizontal speeds $V_{\text {Hmax }}$ by computation. Of course more discussions on the effect of the configuration and the aerodynamic characteristics of missiles should be required. But in this paper, the methodology of virtual tornado generation and the calculation of debris flight are focused on. Therefore the model of missile was simplified following the reference calculations by Simiu and Scanlan (1996) which can be compared with.

Table 2.

Table 3.

The interaction forces between the missiles and the wind were ignored in the calculation of vortex. The unsteady flow field of the vortex was generated in the calculation region shown in Fig. 1. The time series of wind velocity $\mathbf{U}$ in the $X-Y-Z$ coordinate system moving with the vortex (Fig. 7) were recorded. The vortex moved along the $x$ coordinate of the absolute frame with the translational speed $V_{\text {tr }}$. The flow field of a well-developed vortex was used for the computation of the flying debris. The wind velocity $\mathbf{v}_{W}$ relative to the absolute frame is the sum of the wind velocity $\mathbf{U}$ and the translational speed $V_{\mathrm{tr}}$. The numerical integration of Equation (6) was carried out by a linear acceleration method with the time step $\Delta \tilde{t}=0.005$. We used the maximum mean tangential speed $V_{\text {tmax }}$ as $V_{0}$ for the Tachikawa number $T$ a. Missiles were released in the vortex at $z=40 \mathrm{~m}$. The initial conditions of the missiles were $u_{M}=v_{M}=w_{M}=0$ where $u_{M}, v_{M}, w_{M}$ are the missile velocity components along the $x, y, z$ axes of the absolute frame. Also at $t=0$ the center of the vortex coincided with the origin 0 of the absolute coordinate axes. Fig. 10 shows the computed trajectories of missiles released over a uniformly distributed range of positions in the horizontal plane at $Z=40 \mathrm{~m}$ at the same time. Missile $A$ is relatively light and prone to fly further and faster. The computed trajectories of missiles $\mathrm{B}$ released from a single location at $(X, Y, Z)=\left(0,-R_{\operatorname{tmax}}, 40\right)$ in a Type I vortex at different times are shown in Fig. 11. The probability distribution of maximum horizontal speed $V_{\mathrm{Hmax}}$ was obtained with 5,100 missiles release. The probability represents the ratio of the number of missiles with the maximum horizontal speed $v_{\mathrm{Hmax}}$ to that of missiles released during the passage of tornado. Fig. 12 shows the distribution of the mean, the standard deviation and the maximum values of $V_{\text {Hmax }}$ for the missiles released at various points uniformly distributed in the horizontal plane at $Z=40 \mathrm{~m}$. The contours were plotted corresponding to the initial position of the missiles. The computed maxima of $v_{\mathrm{Hmax}}$ for different vortex types and missile types are summarized in Table 3 . Fig. 12 shows that the missiles released near $(X, Y)=(0,-R$ tmax to $\left.2 R_{\operatorname{tmax}}\right)$ have large values of horizontal maximum speed. This is likely caused by the large mean wind speed in the region with the maximum tangential mean wind speed as shown in Fig. 6 (c). And the missiles released near the core of the vortex have large deviations, 
which is most likely due to the large velocity gradients and large magnitude of the instantaneous wind velocity in this region as shown in Fig. 6 (f) to (k).

Fig. 10.

Fig. 11.

Fig. 12.

\section{CONCLUSIONS}

The unsteady flow fields of a tornado-like vortex were generated by a numerical tornado simulator. The wind characteristics in the vortex were examined. The characteristics of missiles and vortices were arranged as equivalent to the design-basis tornado and tornado missiles for nuclear power plants in the USNRC regulatory guide. The trajectories of the missiles released in the vortices were computed and the statistical distributions of maximum horizontal speeds were obtained. The missiles released near the range from one to two times of the radius of the maximum tangential speed have the largest value of maximum horizontal speed and the missiles released near the core of the vortex have large deviations. This is likely caused by the large mean wind speed in the region with the maximum tangential mean wind speed, the large velocity gradients and large magnitude of the instantaneous wind speed near the core.

In this paper, the model of missile was simplified because the methodology of virtual tornado generation and the calculation of debris flight were focused on. The author wants to study on the effect of the configuration and the aerodynamic characteristics of missiles in the future work.

\section{ACKNOWLEDGEMENT}

This work was supported by JSPS KAKENHI Grant \#20560519.

\section{REFERENCES}

English, E. C., Holmes, J. D., 2005. Non-dimensional solutions for trajectories of wind-driven compact objects, Proceedings of The Fourth European and African Conference on Wind Engineering.

Kajishima, T., 1999. Numerical Simulation of Turbulent Flows, Youkendou, in Japanese.

Lin, N., Holmes J. D., Letchford, C. W., 2007. Trajectory of windborne debris and applications to impact testing, J. Structural Eng. ASCE, 133(2), 274-282.

Holmes, J. D., 2004. Trajectories of spheres in strong winds with application to wind-borne debris, Journal of Wind Engineering and Industrial Aerodynamics 92, 9-22.

Holmes, J. D., English, E. C., Letchford, C., 2004. Aerodynamic forces and moments on cubes and flat plates, with applications to wind-borne debris, Summary Papers of the 5th International Colloquium on Bluff Body Aerodynamics and Applications, 103-106.

Holmes, J. D., Baker, C. J., Tamura ,Y., 2006. Short note Tachikawa number: A proposal, Journal of Wind Engineering and Industrial Aerodynamics 94, 41-47. 
Kuai, L., F. L. Haan, Jr., W. A. Gallus, Jr., and Sarkar, P. P., 2008. CFD Simulations of the flow field of a laboratory-simulated tornado for parameter sensitivity studies and comparison with field Measurements, Wind and Structures, 11(2), 75-96.

Maruyama, T., 2009. A Numerically Generated Tornado-like Vortex by Large Eddy Simulation, Proceedings of Seventh Asia-Pacific Conference on Wind Engineering, Taipei Taiwan, 2009.8, pp. 349-352.

Monji, N., Mitsuta, Y., 1985. A laboratory experiment on the multiple structure in tornado-like vortices, Annual report of D.P.R.I. Kyoto University, 28(B-1) , 427-436.

Richards, P.J., Williams, N., Laing, B., McCarty, M., Pond, M., 2008. Numerical calculation of the 3dimensional motion of wind-borne debris, J. Wind Eng. and Ind. Aerody., 96, 2188-2202.

Simiu, E. and Cordes, M., 1976. Tornado-borne missile speeds, NBSIR 76-1050, National Bureau of Standards, Washington, DC.

Simiu, E., Scanlan, R. H., 1996. Wind effects on structures, A Wiley-Interscience Publication, John Wiley \& Sons Inc., 565.

Tachikawa, M., 1983. Trajectories of flat plates in uniform flow with application to wind-generated missiles, Journal of Wind Engineering and Industrial Aerodynamics 14, 443-453.

Uchida, T., Ohya, Y., 2003. Large-eddy simulation of turbulent airflow over complex terrain, J. Wind Eng. and Ind. Aerody., 91, 219-229.

U. S. Nuclear Regulatory Commission, March 2007 Revision 1. Regulatory Guide 1.76, Design-basis tornado and tornado missiles for nuclear power plant, Office of Nuclear Regulatory Research, 6-8.

Wang, K,. and Letchford, C. W., 2003. Flying debris behaviour, 11th International Conference on Wind Engineering, Lubbock, Texas Proceedings 2, 1663-1670.

Wills, J. A. B., Lee, B. E., and Wyatt, T. A., 2002. A model of wind-borne debris damage, Journal of Wind Engineering and Industrial Aerodynamics 90, 555-565. 


\section{Captions of tables}

Table 1. Parameters of calculation conditions

Table 2. Characteristics of vortex

Table 3. Parameters and computed maxima of maximum horizontal speed $V_{\mathrm{Hmax}}$ for selected missiles 
Table 1. Parameters of calculation conditions

\begin{tabular}{lcccc}
\hline Type of vortex core & $\begin{array}{c}\text { single without } \\
\text { mean downflow }\end{array}$ & $\begin{array}{c}\text { single with } \\
\text { mean downflow }\end{array}$ & multiple & swirling \\
Figure number & 2 & 3 & 4 & 5 \\
Radius of exhaust outlet $: R_{\mathrm{t}}$ & $0.05 \mathrm{~m}$ & $0.05 \mathrm{~m}$ & $0.05 \mathrm{~m}$ & $0.05 \mathrm{~m}$ \\
Radius of convection region $: R_{\mathrm{cvt}}$ & $0.15 \mathrm{~m}$ & $0.6 \mathrm{~m}$ & $0.6 \mathrm{~m}$ & $0.6 \mathrm{~m}$ \\
Radius of opening between & & & & \\
$\quad$ convection and convergence region $: R_{\mathrm{ud}}$ & $0.15 \mathrm{~m}$ & $0.15 \mathrm{~m}$ & $0.15 \mathrm{~m}$ & $0.15 \mathrm{~m}$ \\
Height of convection region $: H_{\mathrm{c}}$ & $0.6 \mathrm{~m}$ & $0.6 \mathrm{~m}$ & $0.8 \mathrm{~m}$ & $0.8 \mathrm{~m}$ \\
Height of convergence region $: H_{\mathrm{d}}$ & $0.2 \mathrm{~m}$ & $0.2 \mathrm{~m}$ & $0.1 \mathrm{~m}$ & $0.1 \mathrm{~m}$ \\
Half width of convergence region $: D$ & $0.6 \mathrm{~m}$ & $0.6 \mathrm{~m}$ & $0.6 \mathrm{~m}$ & $0.6 \mathrm{~m}$ \\
Wind speed of exhaust outlet $: W_{0}$ & $1.0 \mathrm{~m} / \mathrm{s}$ & $1.0 \mathrm{~m} / \mathrm{s}$ & $1.0 \mathrm{~m} / \mathrm{s}$ & $1.0 \mathrm{~m} / \mathrm{s}$ \\
Maximum value of the maximum & & & & \\
$\quad$ mean tangential speed $: V_{\text {tmax }}$ & $0.31 \mathrm{~m} / \mathrm{s}$ & $0.25 \mathrm{~m} / \mathrm{s}$ & $0.28 \mathrm{~m} / \mathrm{s}$ & $0.36 \mathrm{~m} / \mathrm{s}$ \\
Use of free boundary conditions & Yes & Yes & Yes & No \\
Use of Dirichlet boundary conditions & Yes & Yes & Yes & Yes \\
Total area of the Dirichlet boundary $: A_{\text {Dir }}$ & $1.7 D H_{\mathrm{d}}$ & $1.7 D H_{\mathrm{d}}$ & $1.7 D H_{\mathrm{d}}$ & $3.4 D H_{\mathrm{d}}$ \\
Tangential wind speed at Dirichlet boundary & $0.0 \mathrm{~m} / \mathrm{s}$ & $0.0 \mathrm{~m} / \mathrm{s}$ & $0.0 \mathrm{~m} / \mathrm{s}$ & $0.0 \mathrm{~m} / \mathrm{s}$ \\
Normal wind speed at Dirichlet boundary & $1.0 \mathrm{~m} / \mathrm{s}$ & $1.0 \mathrm{~m} / \mathrm{s}$ & $1.0 \mathrm{~m} / \mathrm{s}$ & $Q / A_{\text {Dir }}$ \\
Swirl ratio $: S$ & 0.1 & 0.2 & 1.0 & 0.7 \\
Reynolds number $: R e$ & 620 & 760 & 1800 & 1660 \\
\hline
\end{tabular}


Table 2. Characteristics of vortex

\begin{tabular}{lccc}
\hline \multicolumn{1}{c}{ Vortex Type } & I & II & III \\
Translational speed, $V_{\text {tr }}(\mathrm{m} / \mathrm{s})$ & 21 & 18 & 14 \\
Maximum tangential speed, $V_{\text {tmax }}(\mathrm{m} / \mathrm{s})$ & 82 & 72 & 57 \\
Radius of maximum tangential speed, $R_{\mathrm{tmax}}(\mathrm{m})$ & 45.7 & 45.7 & 45.7 \\
\hline
\end{tabular}


Table 3. Parameters and computed maxima of maximum horizontal speed $V_{\text {Hmax }}$ for selected missiles

\begin{tabular}{|c|c|c|c|c|c|c|c|c|c|}
\hline \multirow{3}{*}{$\begin{array}{c}\text { Missile type } \\
\text { A }\end{array}$} & \multirow[t]{2}{*}{$C_{\mathrm{D}}$} & \multirow{2}{*}{$\begin{array}{c}m \\
(\mathrm{~kg})\end{array}$} & \multirow{2}{*}{$\begin{array}{l}C_{\mathrm{D}} A / m \\
\left(\mathrm{~m}^{2} / \mathrm{kg}\right)\end{array}$} & \multicolumn{3}{|c|}{$\begin{array}{c}T_{\mathrm{a}} \\
\text { vortex }\end{array}$} & \multicolumn{3}{|c|}{$\begin{array}{l}\operatorname{maxima} \text { of } \nu_{\operatorname{Hmax}}(\mathrm{m} / \mathrm{s}) \\
\text { vortex }\end{array}$} \\
\hline & & & & Type I & Type I & Type III & Type I & Type I & Type III \\
\hline & 2.0 & 14 & 0.0270 & 5.69 & 4.39 & 2.75 & 91 & 72 & 67 \\
\hline B & 2.0 & 1810 & 0.0070 & 1.48 & 1.14 & 0.71 & 65 & 56 & 48 \\
\hline
\end{tabular}




\section{Captions}

Fig. 1. Numerical tornado simulator.

Fig. 2. Configuration and boundary conditions of calculation region with plots of instantaneous contours of low pressure regions and wind vectors near the ground : single core type without mean down flow region in the core.

Fig. 3. Configuration and boundary conditions of calculation region with plots of instantaneous contours of low pressure regions and wind vectors near the ground : single core type with mean down flow region in the core.

Fig. 4. Configuration and boundary conditions of calculation region with plots of instantaneous contours of low pressure regions and wind vectors near the ground : multiple core type.

Fig. 5. Configuration and boundary conditions of calculation region with plots of instantaneous contours of low pressure regions and wind vectors near the ground : swirling core type.

Fig. 6. Distributions of velocity and pressure field of single core two cell type shown in Figure 3 in a vertical plane.

Fig. 7. Coordinates systems and the profiles of azimuthally averaged mean values of maximum mean tangential speed $V_{\mathrm{tm}}$, the maximum tangential speed radius $R \mathrm{tm}$ at which $V_{\mathrm{tm}}$ occurs, the radial speed $V_{\mathrm{rm}}$, the vertical speed $W_{\mathrm{tm}}$ and Swirl ratio $S$ at $R_{\mathrm{tm}}$.

Fig. 8. Variation of azimuthally averaged mean values of tangential speed $V_{\mathrm{t}} / V_{\mathrm{tmax}}$, radial speed $V_{\mathrm{r}} / V_{\mathrm{tmax}}$, vertical speed $W / V_{\mathrm{tmax}}$, horizontal speed $U V / V_{\mathrm{tmax}}$, absolute speed $U V W / V_{\mathrm{tmax}}$ and differential pressure $C_{\mathrm{p}}=2 \Delta P / \rho V_{\operatorname{tmax}}^{2}$ from the surrounding mean pressure as a function of radial distance $R$ at the height where the maximum tangential speed occurs.

Fig. 9 Variation of azimuthally averaged mean values of tangential speed $V_{\mathrm{t}}$ as a function of radial distance $R$.

Fig. 10. Trajectories of missiles released in the vortex Type I at different positions at $Z=40 \mathrm{~m}$.

Fig. 11. Trajectories of Type B missiles released at $(X, Y, Z)=\left(0,-R_{t m a x}, 40\right)$ in the Type I vortex at different times and the probability of maximum horizontal speed $V_{\mathrm{Hmax}}$ of missiles. Statistics were obtained for 5,100 missiles.

Fig. 12. Distribution of the mean, the standard deviation and the maximum of the horizontal speed $V_{\text {Hmax. The Type B }}$ missiles were released in the Type I vortex at $Z=40 \mathrm{~m}$. Statistics were obtained for 1,400 missiles released at different times at a point. Contours are plotted corresponding to the release points uniformly distributed as indicated by the grid in the figure. Values in the figure are in units of $\mathrm{m} / \mathrm{s}$. 


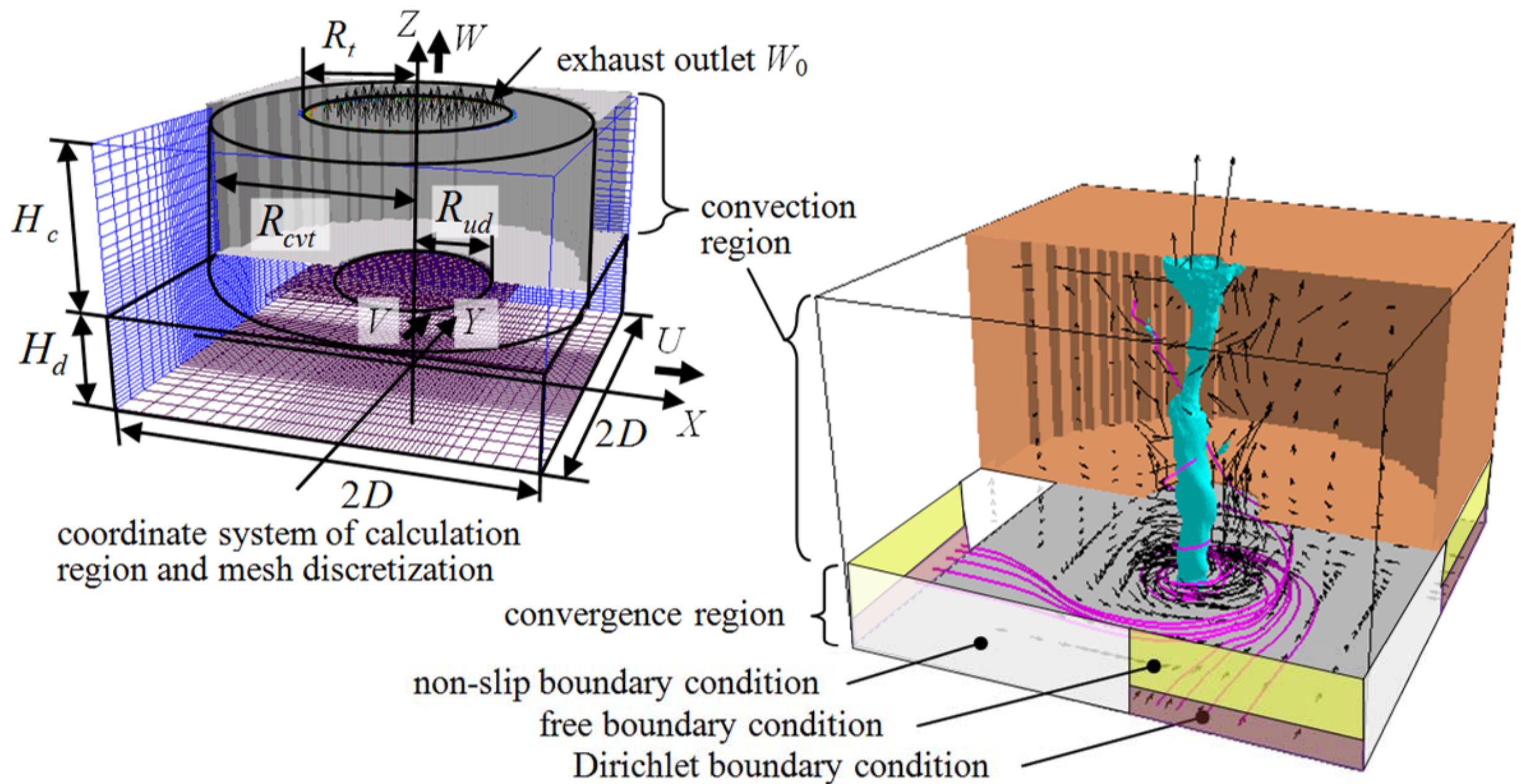
snapshot of a generated tornado-like vortex

Fi g. 1. Numeri cal tor nado si mul at or . 

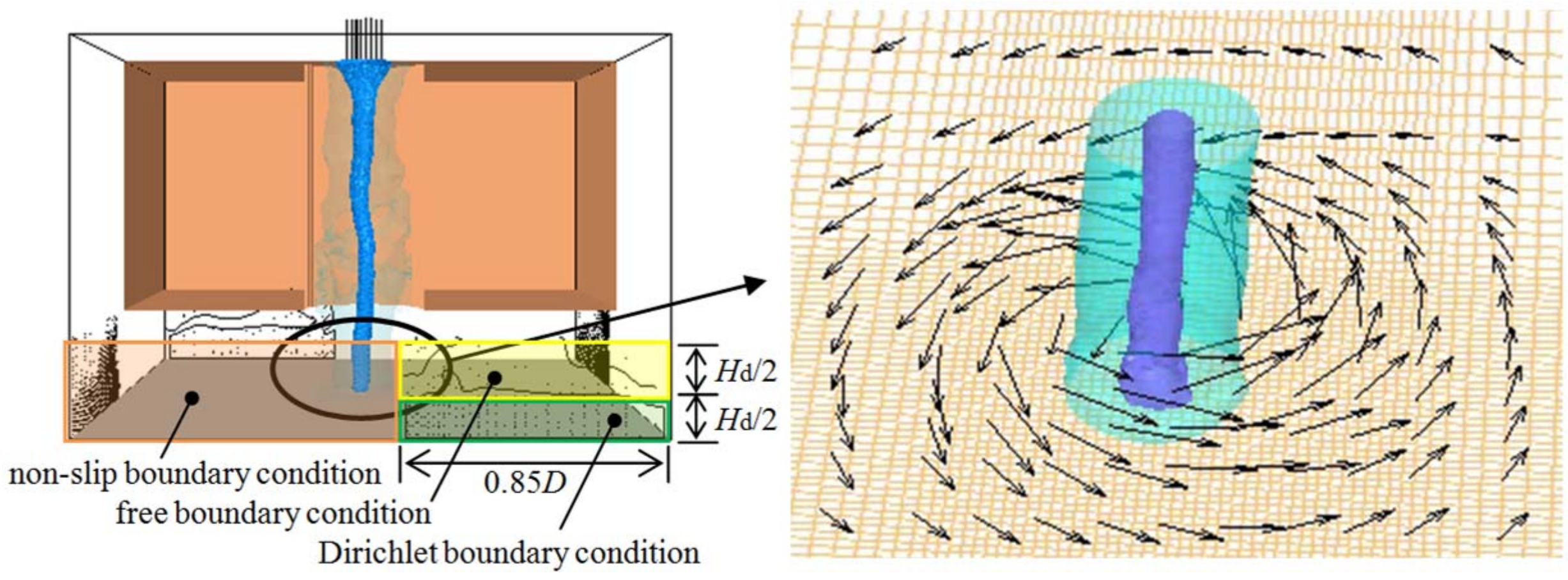

Fig. 2. Conf $i$ gur at $i$ on and boundary conditi ons of cal cul at $i$ on regi on with pl ot s of i nst ant aneous cont ours of $I$ on pressure regi ons and wi nd vect or s near the ground: si ngl e core type wi thout mean down fl ow regi on in the core. 

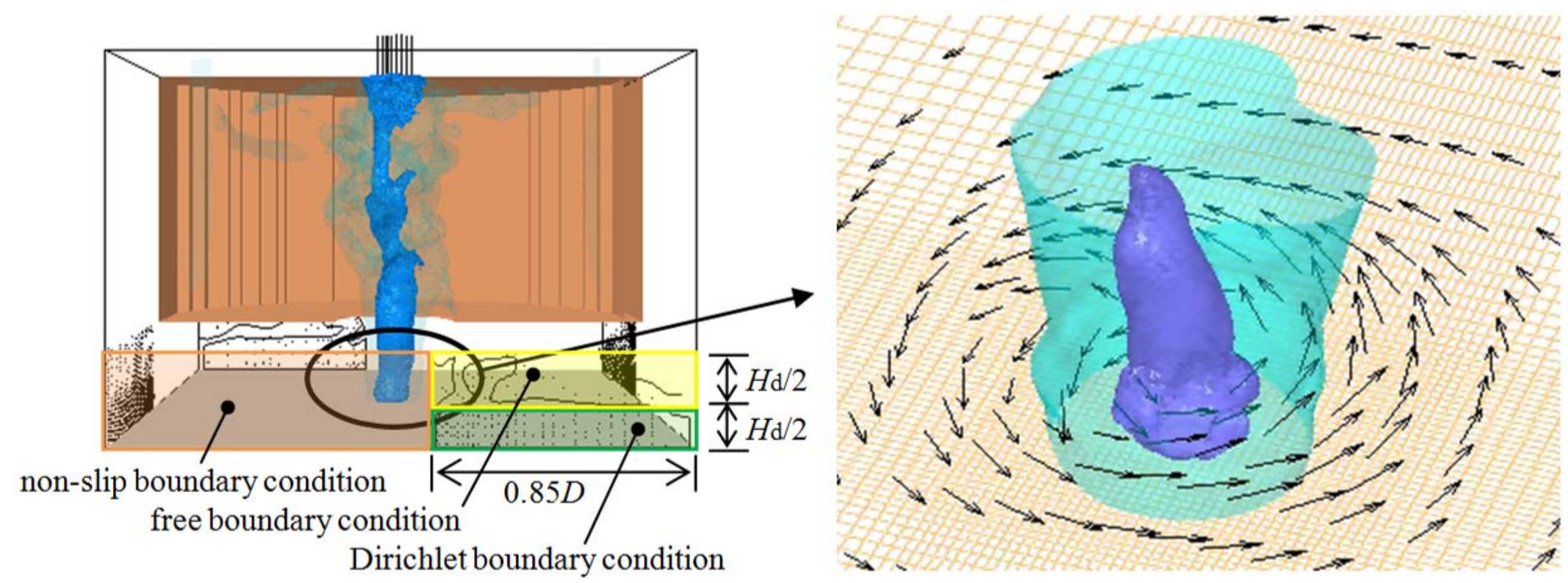

Fig. 3. Conf $i$ gur at $i$ on and boundary condi ti ons of cal cul at i on regi on with pl ot s of i nst ant aneous cont our s of $I$ ow pressure regi ons and wi nd vect or s near the ground: si ngle core type with mean down fl ow regi on in the core 

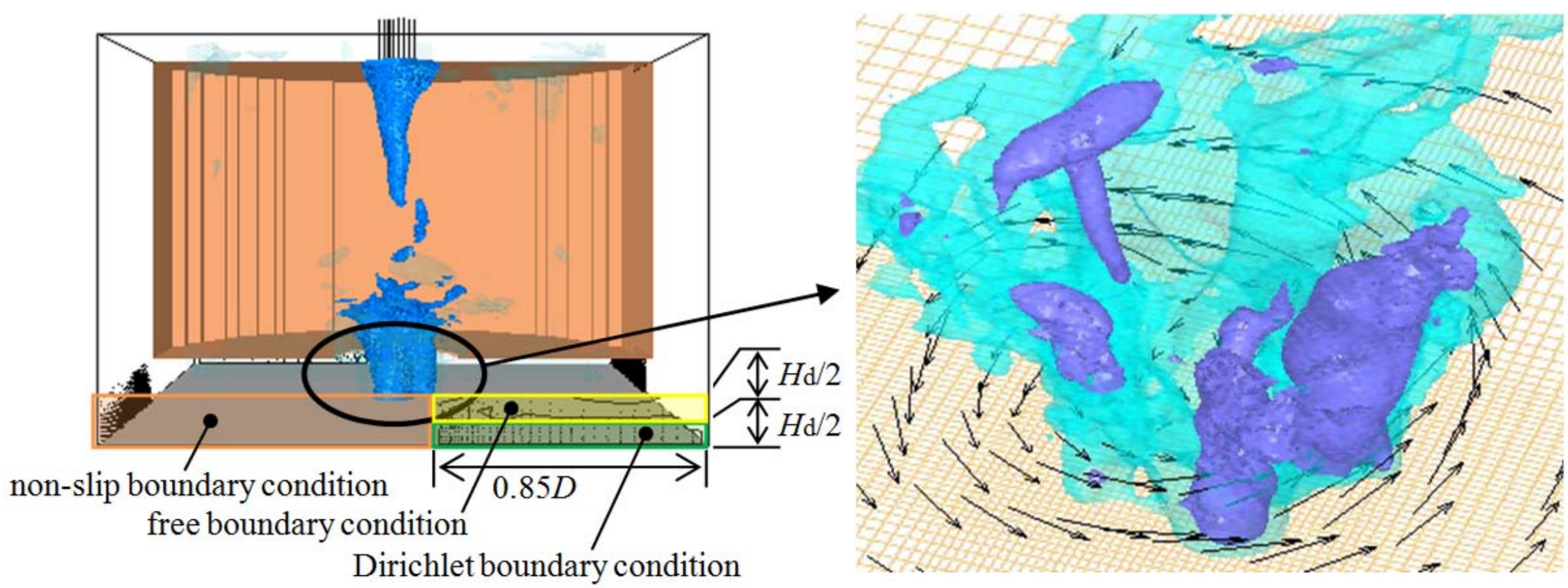

Fig. 4. Conf $\mathrm{i}$ gur at $\mathrm{i}$ on and boundary condi ti ons of cal cul at $\mathrm{i}$ on regi on with pl ot $\mathrm{s}$ of i nst ant aneous cont our s of $\mathrm{I}$ ow pressure regi ons and wi nd vect or s near the ground : mul ti ple core type. 

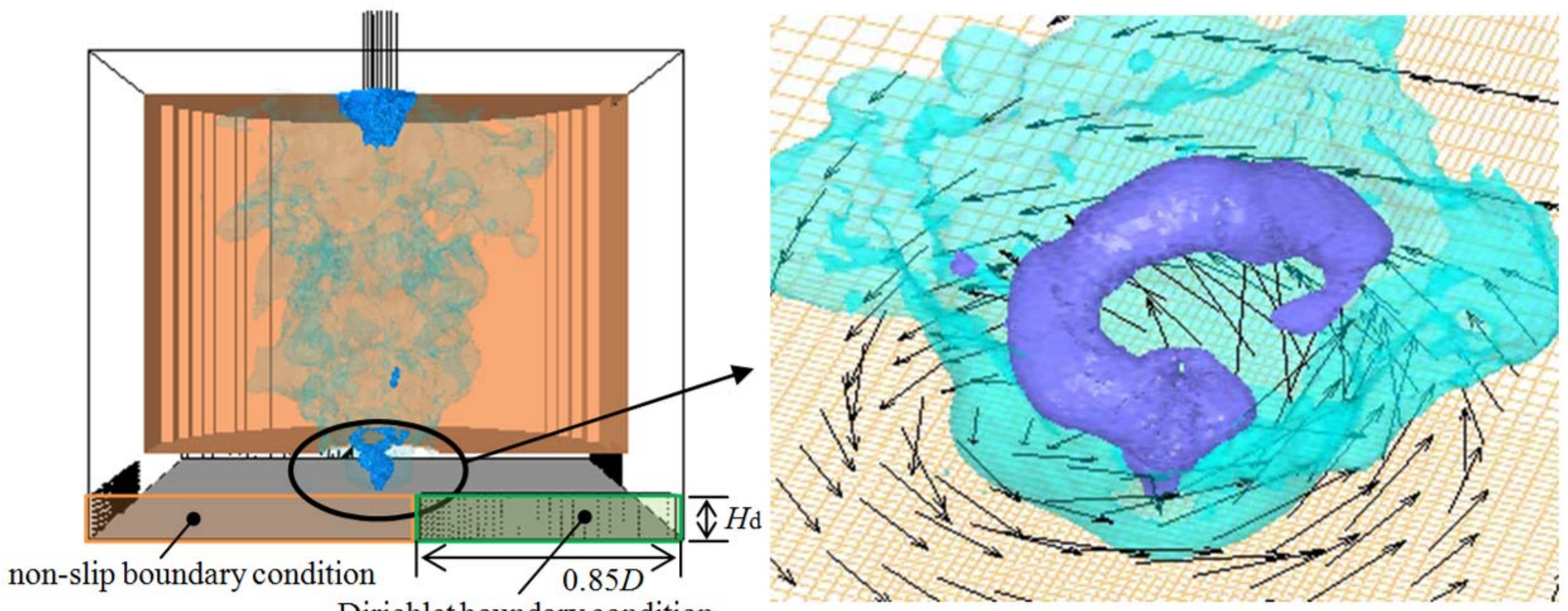

Dirichlet boundary condition

Fig. 5. Conf $\mathrm{i}$ gur at $\mathrm{i}$ on and boundary condi ti ons of cal cul at i on regi on with pl ot s of i nst ant aneous cont our s of $I$ ow pressure regi ons and wi nd vect or s near the ground: swi rling core type. 


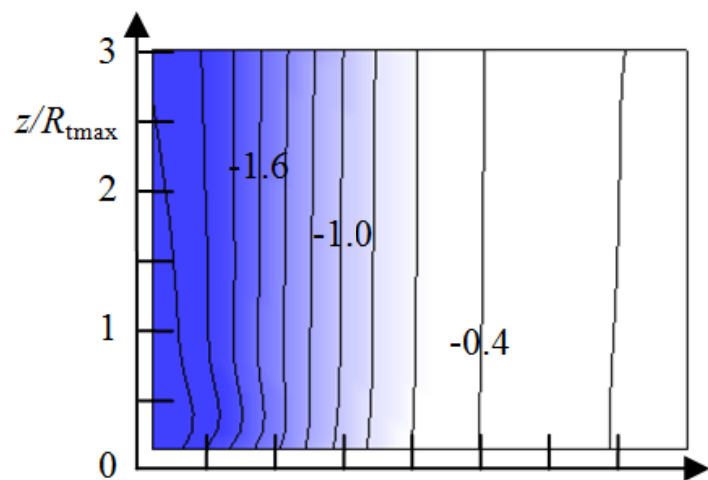

a. azimuthally averaged mean pressure, $2 P / \rho V$ tmax $^{2}$

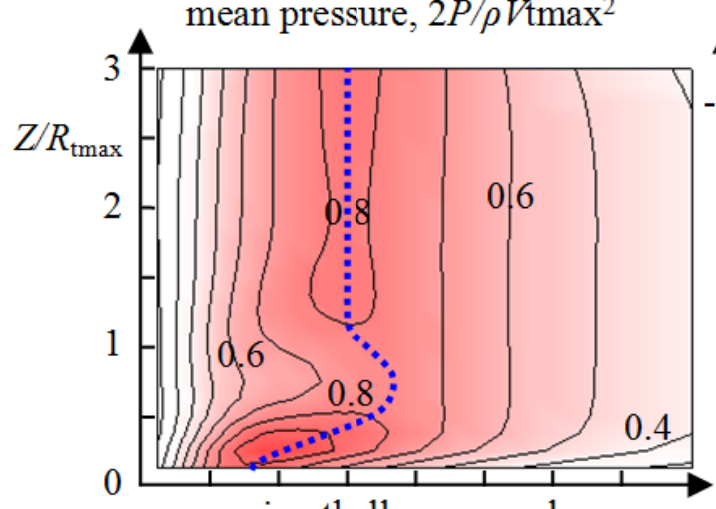

c. azimuthally averaged mean tangential speed, $V_{\mathrm{t}} / V_{\mathrm{tmax}}$

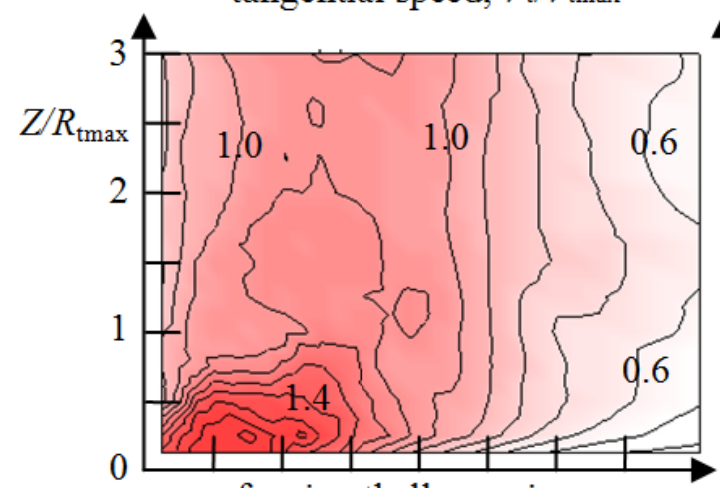

f. azimuthally maximum tangential speed, $V_{\mathrm{t}} / V_{\mathrm{t} \max }$

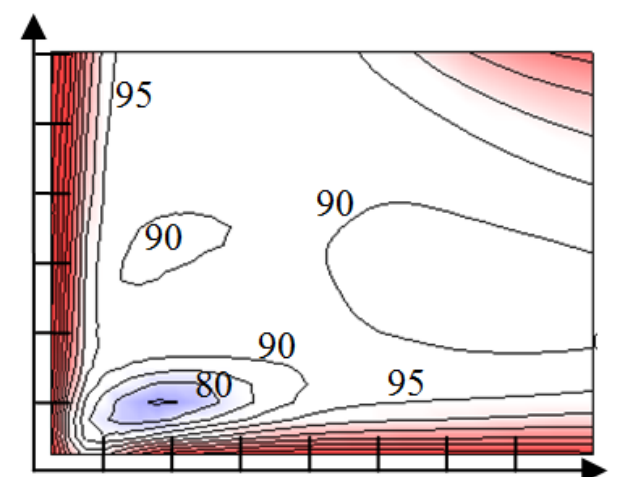

b. azimuthally averaged mean horizontal wind angle $\alpha$ from radial direction

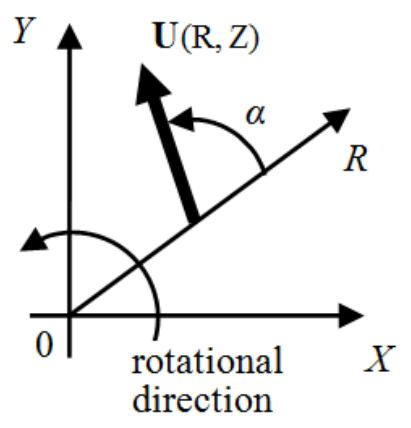

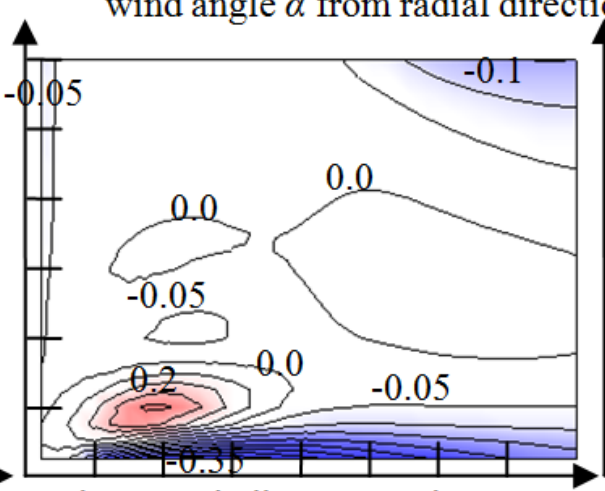

d. azimuthally averaged mean radial speed, $V_{\mathrm{r}} / V_{\mathrm{t} \max }$

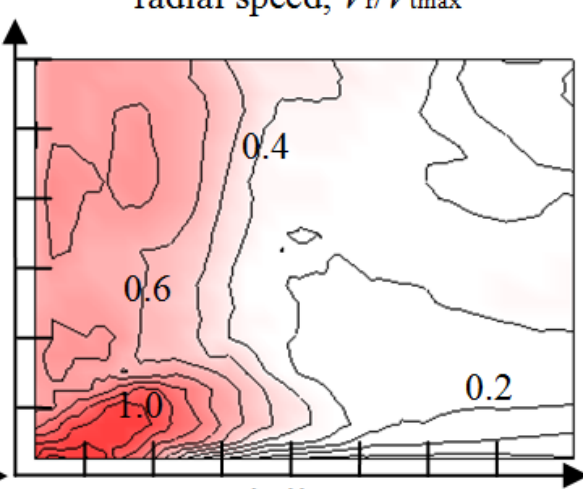

g. azimuthally maximum radial speed, $V_{\mathrm{r}} / V_{\mathrm{t} \max }$

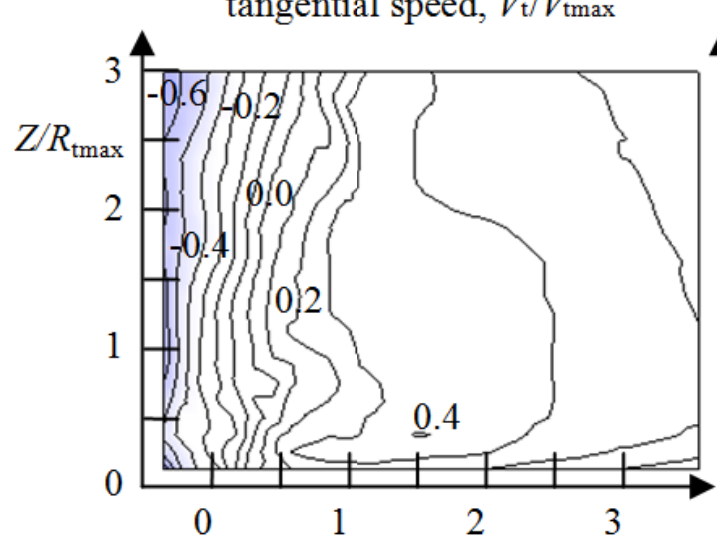

i. azimuthally minimum tangential speed, $V_{\mathrm{t}} / V_{\mathrm{tmax}}$

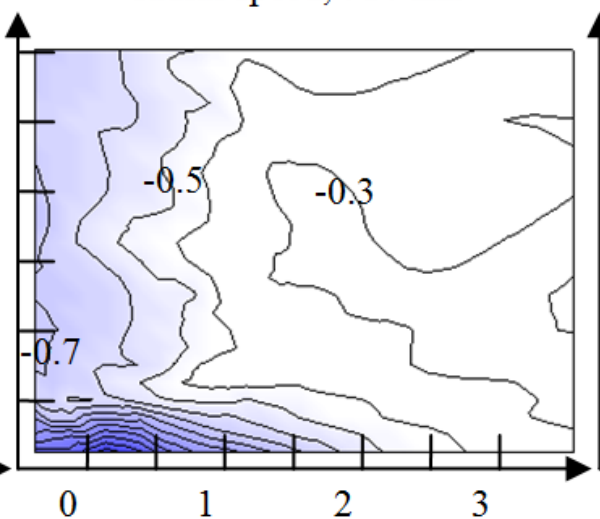

j. azimuthally minimum radial speed, $V_{\mathrm{r}} / V_{\mathrm{t} \max }$

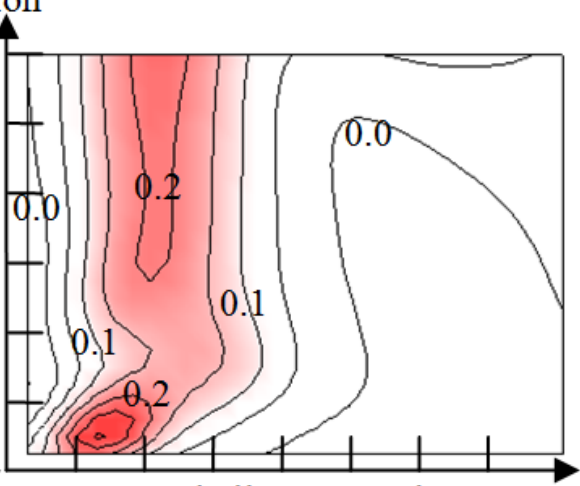

e. azimuthally averaged mean vertical speed, $W / V_{\operatorname{tmax}}$

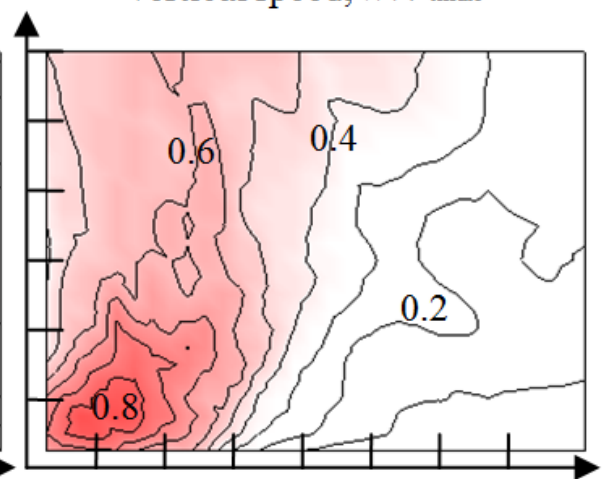

h. azimuthally maximum vertical speed, $W / V_{\operatorname{tmax}}$

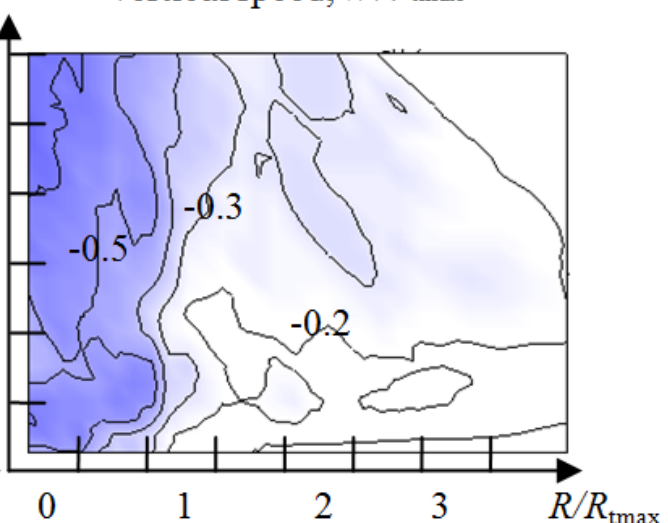

k. azimuthally minimum vertical speed, $W / V_{\mathrm{tmax}}$

Fig. 6. Distributions of vel ocity and pressure field of single core two cel I type shown in Figure 3 in a vertical pl ane. 

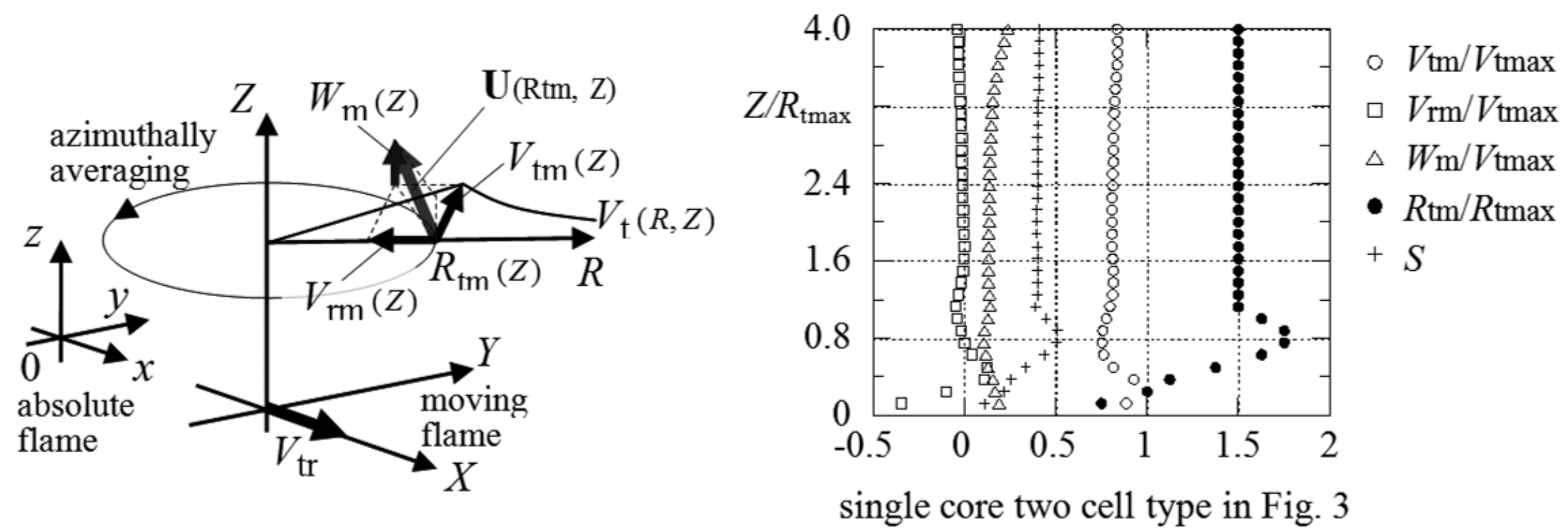

Fig. 7. Coordi nates systems and the profiles of azi muthal ly averaged mean val ues of maxi mum mean tangential speed Vt $m$ the maxi mumtangential speed radi us Rtmat which Vtmoccurs, the radial speed Vrm the vertical speed Wmand Sui rl ratio $S$ at Rt m 


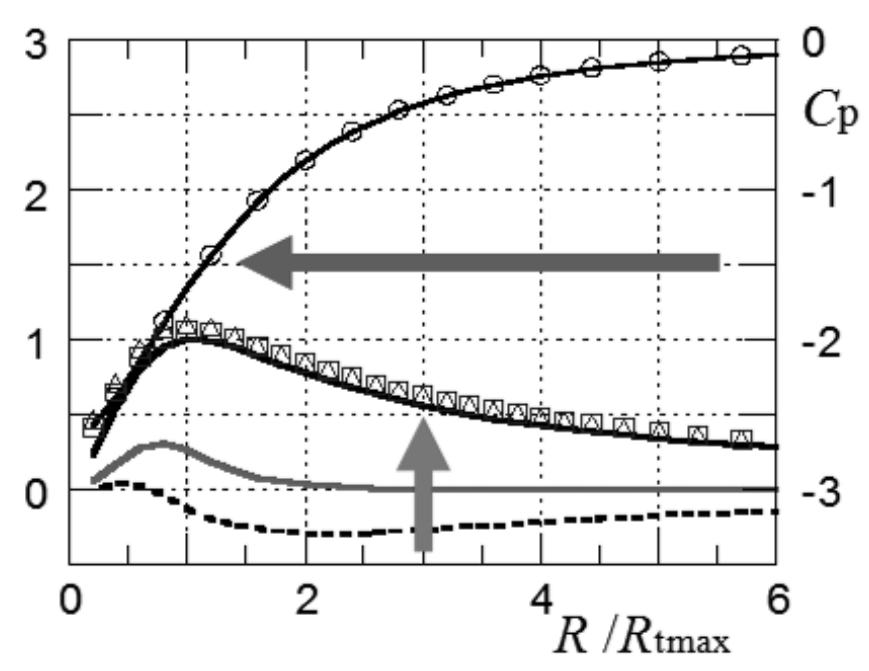

a. single core type without mean down flow region in the core

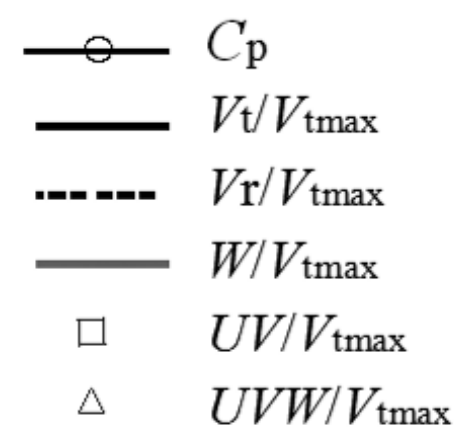

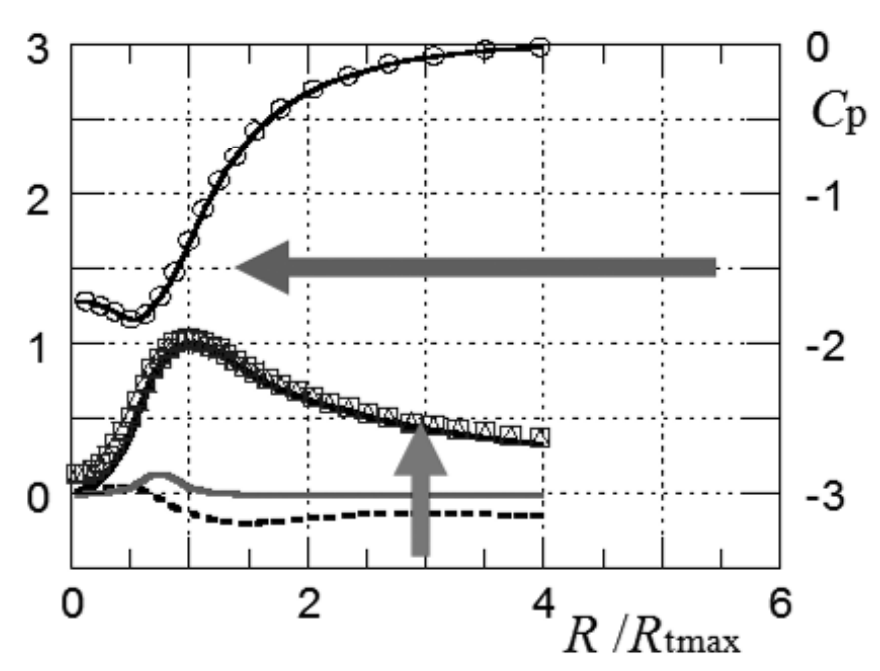

c. multiple core type

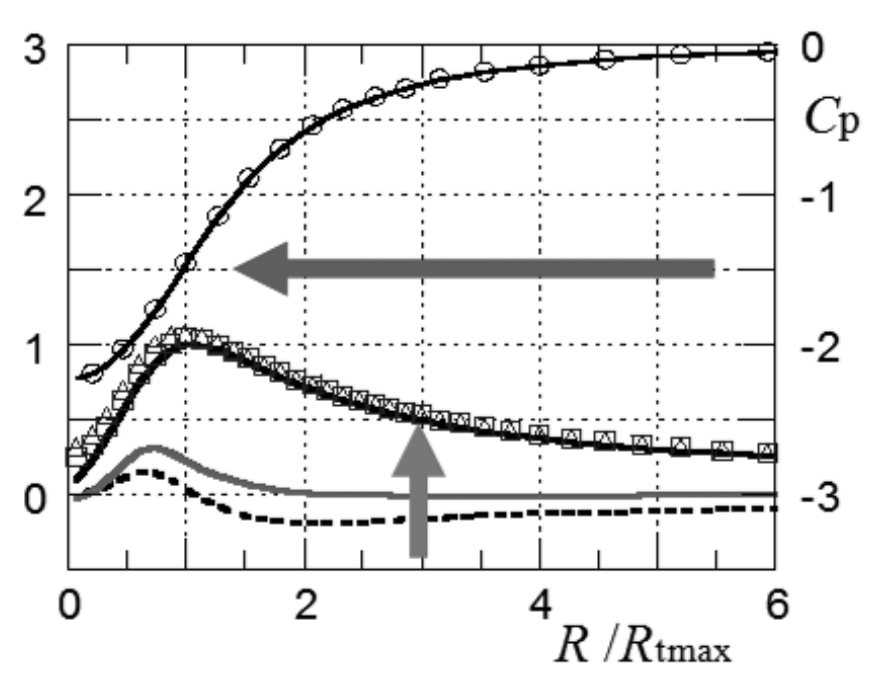

b. single core type with mean down flow region in the core

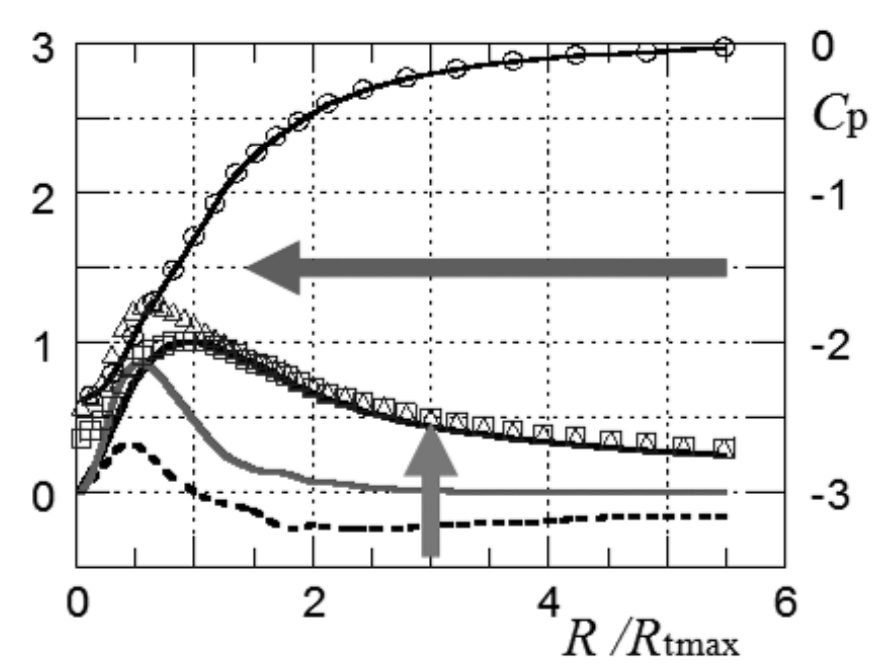

d. swirling core type

Fi g. 8. Vari at $i$ on of azi muthal ly aver aged mean val ues of tangent $i$ al speed Vt $/$ t max, $r$ adi al speed $V r / V t$ max, vertical speed WVt max, hori zont al speed UV/Vt max, absol ut e speed UWVVt max and differenti al pressure $\mathrm{Cp}=2 \mathrm{P} / \rho \mathrm{Vt} \max 2 \mathrm{fr}$ om the sur roundi ng mean pressure as a functi on of radi al di stance at the hei ght where the maxi mumtangenti al speed occurs. 


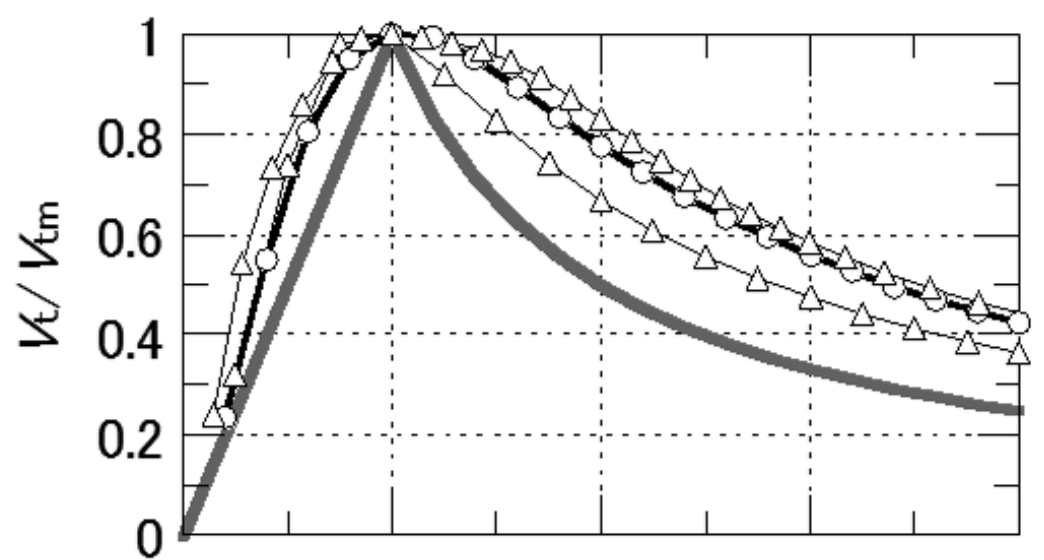

a. single core type without mean - down flow region in the core

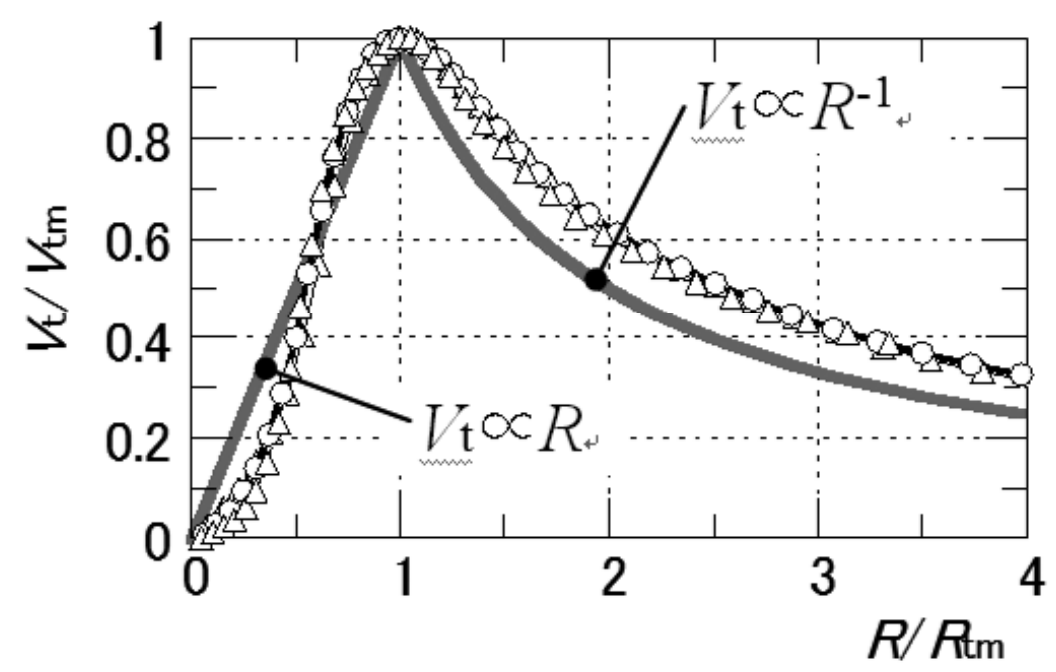

c. multiple core type

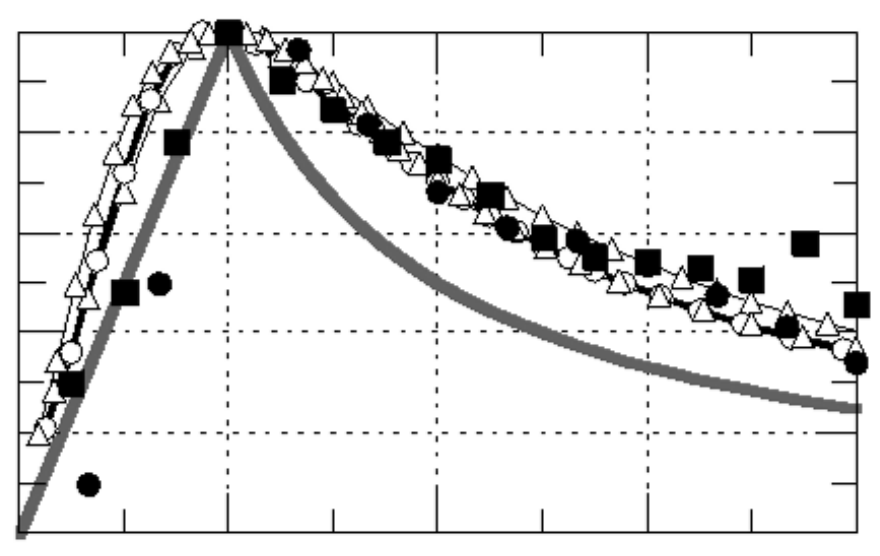

b. single core type with mean down flow region in the core

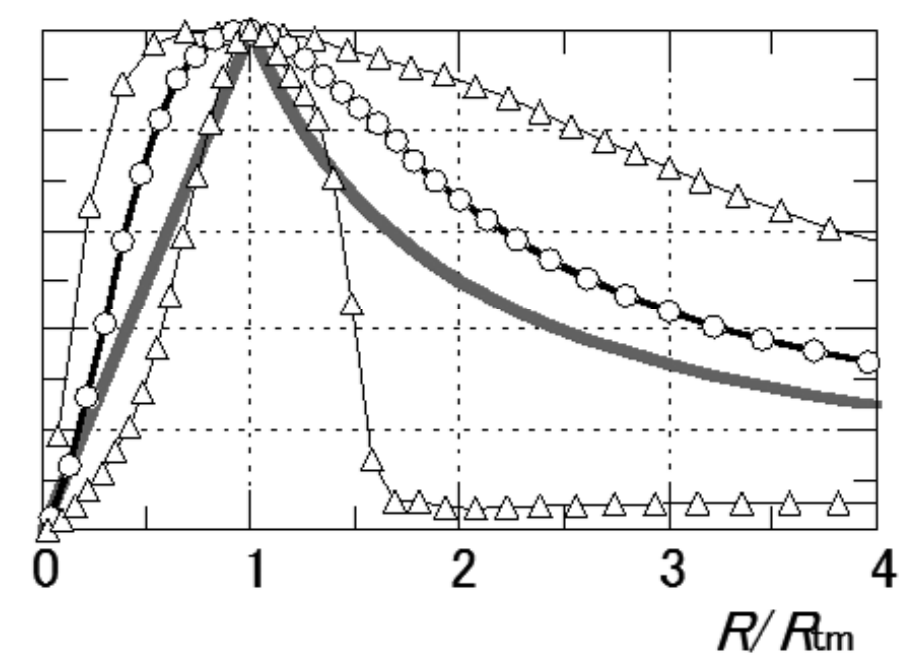

d. swirling core type height

$\square 0.5 R_{\text {tmax }}$

$\longrightarrow 1.0 R_{\text {tmax }}$

$\smile 2.0 R_{\text {tmax }}$

- experiment

- radar-data

Fig. 9 Variation of azi muthal ly aver aged mean val ues of tangential speed Vt as a function of radial distance R. 


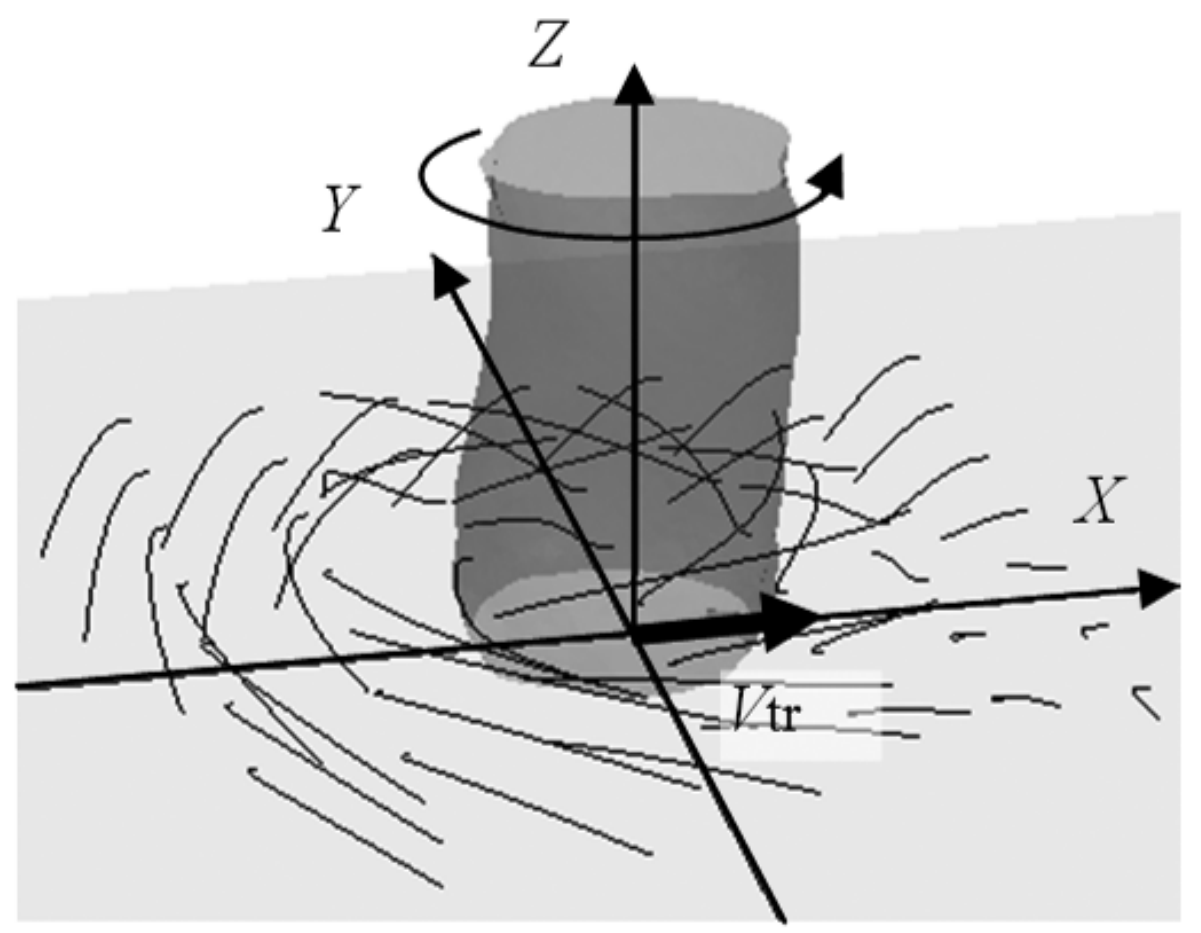

a. Missile A

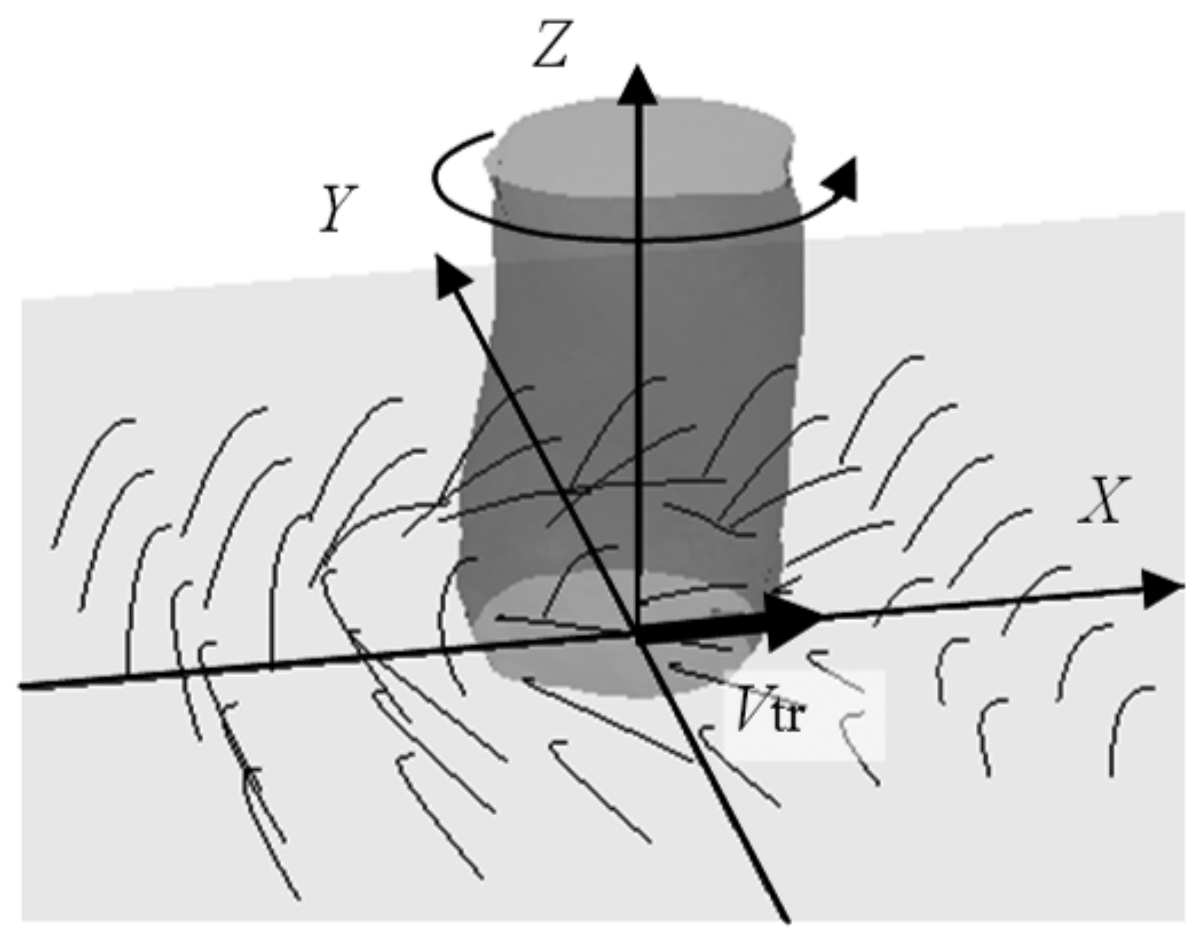

b. Missile B 

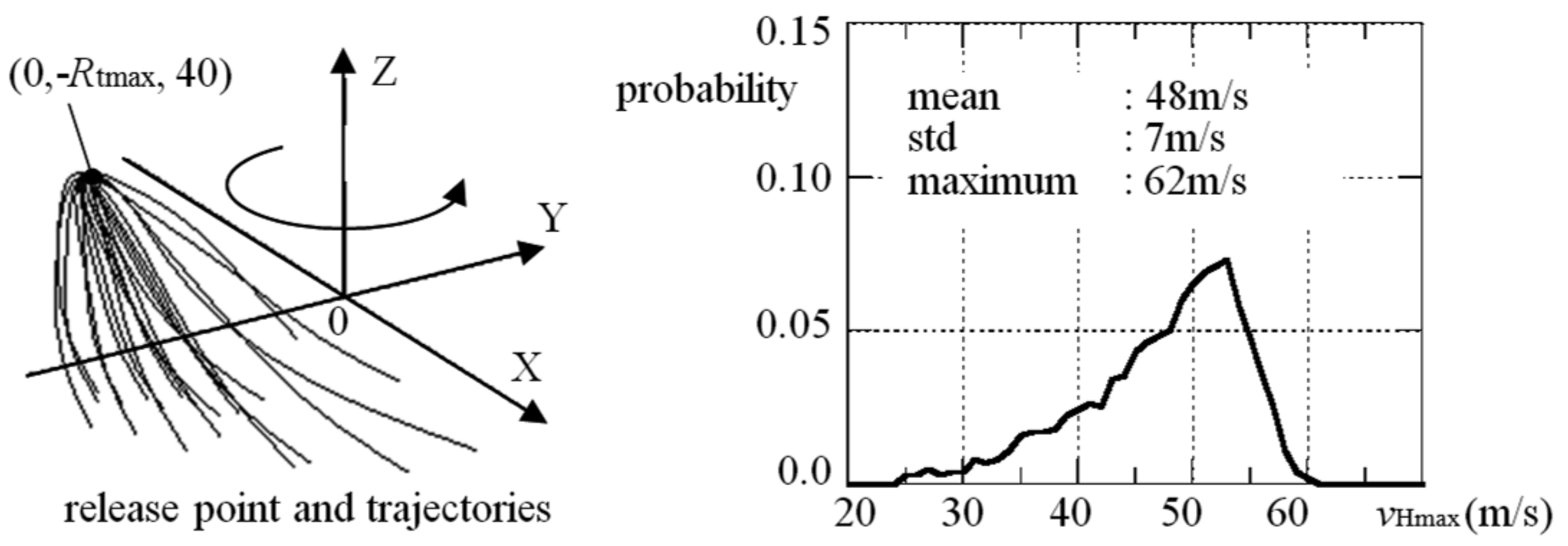

Fig. 11. Traject ories of Type $B$ missiles rel eased at $(X, Y, Z)=(0,-$ Rt $\max , 40)$ in the Type I vortex at different ti mes and the probability of maxi mum horizontal speed vHhax of missiles. Statistics were obtai ned for 5, $100 \mathrm{missiles.}$ 

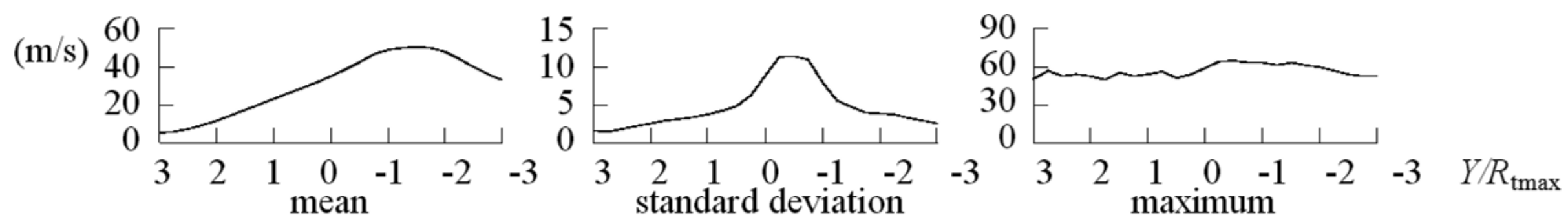
a. profiles of maximum values through the $X$ direction
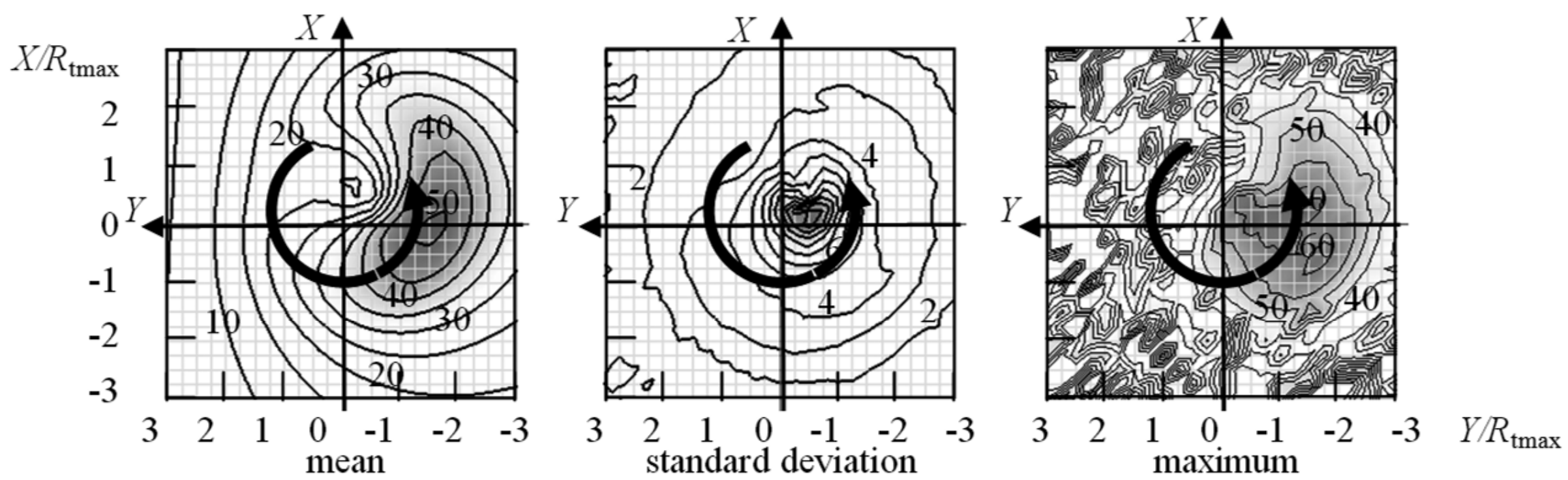

b. 2-dimensional distribution

Fig. 12. Di stributi on of the mean, the standard devi at $i$ on and the maxi mum of the horizontal speed vHmax. The Type $B$ missiles were rel eased in the Type I vortex at Z=40m Statistics were obtai ned for 1,400 missiles rel eased at different ti mes at a point. Contours are pl otted corresponding to the rel ease points uniformy distributed as indicated by the grid in the figure. Val ues in the figure are in units of $\mathrm{m} / \mathrm{s}$. 